\title{
A study on exhaust gas temperature and emission characteristics of a compression ignition engine fueled with transesterified rice bran oil
}

\author{
Sirivella Vijaya Bhaskar ${ }^{*}$ \\ Professor, Department of Mechanical Engineering, Sreenidhi Institute of Science and Technology, Ghatkesar, \\ Hyderabad, India
}

\section{(C2018 ACCENTS}

\begin{abstract}
In recent times, mainly due to diminishing of fossil fuel reserves and increasing population and their living standards causing steep rise in energy consumption. Moreover, the usage of fossil fuels is severely impacting on environmental pollution that changing the climatic conditions, unpredictably. These problems have raised the need of alternative renewable fuel to sustain and meet the present and future energy demand. In the recent time, biodiesel has become a prospective replacement to diesel fuel, as alternative fuel, because of its physio-chemical properties and heating value. The present research study indented to analyse the emission characteristics of direct injection compression ignition engine fuelled with rice bran oil methyl ester (RBOME). The experimental analysis was carried out using a single cylinder, 4-stroke, and water cooled, direct injection diesel engine fuelled with different blends (BR20, BR40, BR60 and BR100) of RBOME at rated engine speed with different load conditions. The results revealed that biodiesel has higher exhaust gas temperature and lower exhaust emissions (carbon monoxide, smoke opacity) except NOx emissions when compared with diesel fuel.
\end{abstract}

\section{Keywords}

Biodiesel, Rice bran oil, Transesterification, Vegetable oil, Emission characteristics, Methyl ester.

\section{Introduction}

At present, the global energy sector is facing problem to provide sustainable and continuation energy to meet the present need. This is because of dwindling of fossil fuel reserves and increased cost of production. On other side, the environmentalists are warning about global increase of environmental temperature which is because of increased air pollution due to exhaust emissions from automotive. Green gas emissions is the notorious gases for ensnare the atmospheric heat that is emitted due to combustion of fossil fuels. To reduce the emissions and meet the current and future energy demand, the biodiesels are the most encouraging and anticipative sustainable energy resource. The past research reviews indicated that diesel engines are most widely used for transportation and agriculture purposes across the globe and emission of diesel engines are one of the main sources for the dangerous effect on environmental pollution and consuming more fuel than any other engines. Hence many countries have encouraged research and development for alternative source of fuel for replacement of diesel fuel.

*Author for correspondence
Biodiesel is a mono alkyl esters derived from vegetable oils or animal fats. It is biodegradable, nontoxic, clean burning and is free of sulfur and aromatics [1-3]. Moreover biodiesels can be used directly in any existing, unmodified diesel engine [4]. Recently investigation on vegetable oils/animal fats for its suitability as biodiesel is because of incessantly availability in the country of production, therefore soybean oil was of principal interest in USA as biodiesel source while many European countries were concerned with rapeseed oil, and tropical countries such as Asian countries prefer to utilize coconut, palm, sunflower, safflower, etc., have also been tested [5, 6]. Recently the research has started with the use of animal fats and waste cooking oils as feedstock's of biodiesel. Canakci [7] did experimental comparison analysis between biodiesel from soybean oil and its 20 per cent blends with No. 2 diesel fuel. The test results demonstrated that the engine performance of the neat biodiesel and its blend was similar to that of No. 2 diesel fuel with virtually the same brake fuel conversion efficiency, and somewhat superior fuel consumption. CO2 emission for biodiesel was slightly higher than for the No. 2 diesel fuel. Compared with diesel fuels, biodiesel released lower exhaust emissions, except 
NOx [7]. Altin et al. [8] examined the impacts of vegetable oil vegetable oil fuels and their methyl esters (cotton seed oil, sun flower oil, soybean oil, refined rapeseed oil, refined corn oil and their methyl esters) on a 4- stroke, single cylinder direct injection diesel engine. The results revealed that from the performance point of view, both vegetable oils and their esters were promising alternatives as fuel for diesel engines. Because of their high viscosity, drying with time and thickening in cold conditions, vegetable oil fuels still have problems like low atomization and heavy particulate emissions [8]. Barsic and Humke [9] exploratory analysis on engine performance and emission characteristics of soya bean oil using a single cylinder, naturally aspirated, DI diesel engine and revealed that in comparison of diesel, thermal efficiency lowered, lower NOx, more $\mathrm{CO}$, more hydrocarbons and more particulates with vegetable oils. Gattamaneni et al. [10] assessed the combustion and exhaust emissions of a direct injection diesel engine fuelled with Rice Bran oil methyl ester and its diesel blends. Rice grain oil methyl ester (RBOME) was inferred through the transesterification procedure and the properties were tantamount with ASTM Bio-diesel guidelines. Tests were directed utilizing stationary diesel motor to assess the attainability of RBOME and its diesel mixes as interchange fills. The ignition delay and its peak heat release for rice bran biodiesel and its diesel mixes were observed to be lower than that of diesel and that the start defer diminishes with increment in RBOME in the mix. It was additionally noticed that, as the measure of RBOME in the mix expanded, the $\mathrm{HC}, \mathrm{CO}$ and residue focuses in the fumes diminished when contrasted with mineral diesel. The NOx discharges of the RBOME and its diesel mixes were noted to be marginally higher than diesel [10]. Nabi et al. [11] performed experimental tests on DI diesel engine fuelled with cotton seed oil biodiesel mixtures and established that the emissions of $\mathrm{CO}$ and $\mathrm{PM}$ were lower than that of pure diesel fuel and NOx level was higher. This is for the reason that biodiesel mixtures contain additional oxygen in their molecules that result incomplete combustion of the fuel and supply the necessary oxygen to convert $\mathrm{CO}$ to $\mathrm{CO} 2$. This additional oxygen is also responsible for higher NOx emission compared to neat diesel fuel. A mixture of $70 \%$ neat diesel and 30\% biodiesel significantly reduced emissions of $\mathrm{CO}$, NOx and particulate matter. The reduction of NOx with biodiesel may be possible with the proper adjustment of injection timing and using exhaust gas recirculation technique [11]. Qi et al. [12] tested the performance and combustion characteristics of diesel engine using soybean biodiesel and revealed that as the engine delivers fuel on volumetric basis and the density of biodiesel is higher than that of diesel, the power output of tested biodiesel engine is approximately the same as diesel engine [12]. Bhaskar [13] has conducted investigation on madhuca indica biodiesel and experiment results revealed that B20M blend of biodiesel has comparable brake thermal efficiency as diesel fuel. $\mathrm{B} 20 \mathrm{M}$ has lowest and B100M has highest BSFC, BSEC among all the tested biodiesel blends. B20M has demonstrated comparable performance as diesel fuel and it can be considered as alternative to diesel [13]. Hasan and Rahman [14] investigated and reported that blends containing up to $30 \%$ biodiesel have almost the same properties as diesel. When compared to diesel, biodiesel-diesel blend provides shorter ignition delay and a reduced heat release rate as well as a slightly higher efficiency by sacrificing a small amount of fuel. The $\mathrm{HC}, \mathrm{CO}$, and PM emissions are reduced to a great extent but the NOx emission becomes slightly higher [14].

\section{Materials and methods}

The present research study used rice bran oil, methanol, sodium hydroxide and distilled water as raw materials. Usually vegetable oils have more viscosity, low volatility and it needs transesterification process which is a benchmark in order to reduce the viscosity, improve the performance of vegetable oil, and eventually prepare biodiesel from oil/fats. The same process was adopted for the present study and prepared RBOME which was used in CIDI engine as biodiesel. As shown in Figure 1, Transesterification is the reaction of fat/oil triglycerides to fatty acid alkyl esters and low molecular weight alcohols in the presence of catalyst [15, 16]. Short chain Alcohols such as methanol, ethanol, and butanol are the most frequently employed in the transesterification process. Methanol is the most widely used alcohol as it is less expensive and easily obtainable [17].

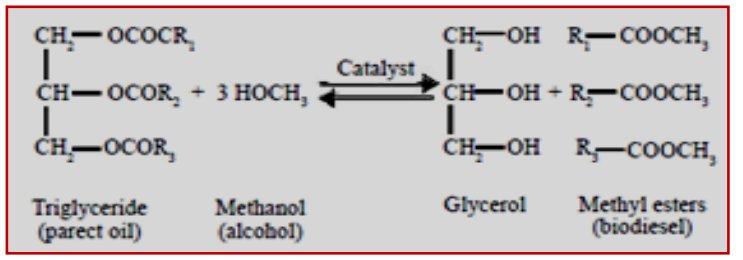

Figure 1 Transesterification process

Methanol produces methyl esters; ethanol produces ethyl esters and is base catalyzed by either potassium or sodium hydroxide. 
Potassium hydroxide has been found to be more suitable for the ethyl ester biodiesel production, but either base can be used for methyl ester production. Table 1 shows the fuel properties.

Table 1 Fuel properties

\begin{tabular}{llll}
\hline Fuel Property & Unit & ASTM standard & RBOME \\
\hline Kinematic Viscosity@ $40^{0} \mathrm{C}$ & $\mathrm{Cst}$ & $\mathrm{D} 445$ & 5.37 \\
Flash Point & ${ }^{0} \mathrm{C}$ & $\mathrm{D} 93$ & 165 \\
Density @ $15^{0} \mathrm{C}$ & $\mathrm{Kg} / \mathrm{m}^{3}$ & $\mathrm{D} 1298$ & 880 \\
Calorific Value & $\mathrm{KJ} / \mathrm{Kg}$ & - & 38952 \\
Cetane Number & - & $\mathrm{D} 613$ & 52 \\
\hline
\end{tabular}

\section{Experimental setup}

For the present study, a single cylinder, 4-stroke, water cooled $3.7 \mathrm{KW}$ diesel engine was used. An eddy current dynamometer was used as loading unit. The instrumentation available in the test rig are used to measure air consumption, fuel consumption, cooling water flow rate, cylinder pressure, exhaust gas temperature. A separate gas analyzer was used which was coupled to the computerized test rig to measure CO, and NOx emissions. A smoke meter was used to measure the smoke density. An oblique manometer was used to measure air consumption. The lubricating oil, fuel and ambient temperatures were measured by thermocouples. The schematic diagram of experimental setup is given in Figure 2.

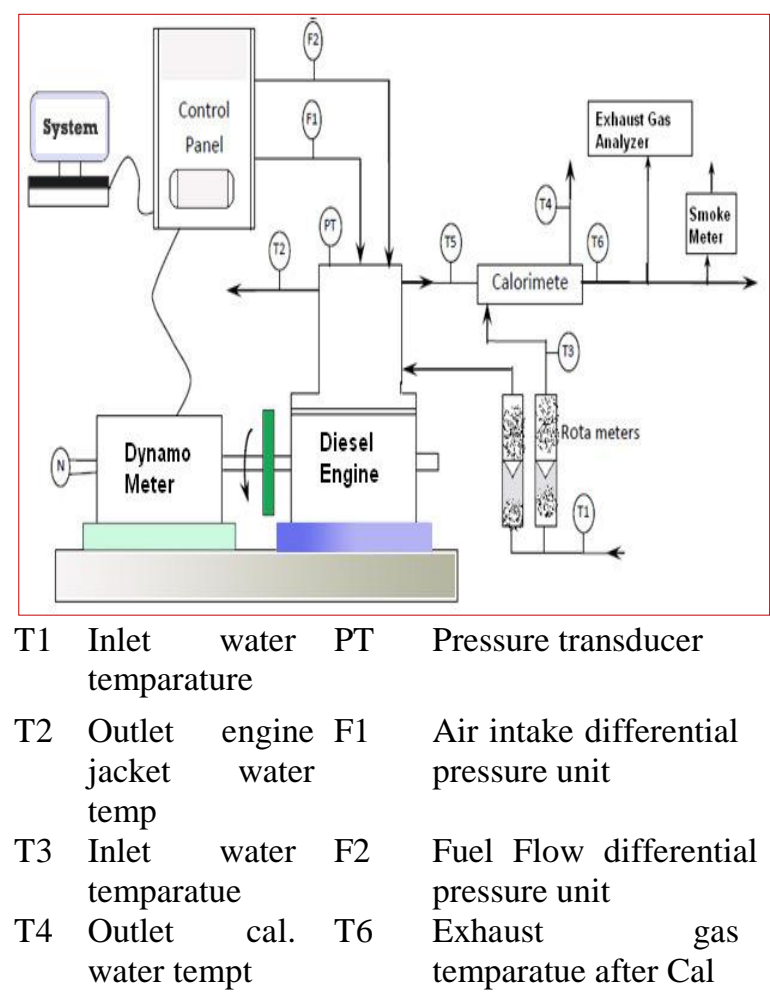

T5 Exhaust gas temparatue before $\mathrm{Cal}$

Figure 2 Schematic diagram of test setup
The test engine was initially operated with diesel for few minutes and once the engine has warmed up, then a series of emission tests were conducted with different load conditions while recording the readings. Subsequently, the same was done again using different blends of rice bran oil biodiesel and the readings of each blend for different load conditions were recorded. For each operation, speed of the engine was verified and maintained almost constant. Each experiment was repeated with similar operating condition and each reading was recorded as arithmetic mean of two readings for accuracy. The test data was then analyzed using graphs and results are given in the subsequent paragraphs for each emission parameter. The emission a characteristic of direct injection compression ignition engine was experimentally analyzed in the present investigation is: exhaust gas temperature (EGT), carbon monoxide (CO), smoke opacity and oxides of nitrogen oxide (NO).

\section{Results and discussion}

\subsection{Exhaust gas temperature}

The EGT for diesel, RBOME and its blends as test fuels at various load conditions is shown in Figure 3. It was observed from the graph that as the engine load increases the EGT increases and increases with the increase of percentage of biodiesel content in blend. All tested fuels have lower EGT values at part load condition and higher values at higher loads.

Diesel has the lowest and net biodiesel has the highest EGT with $11.86 \%$ higher than diesel at full load. The B20R has closest EGT to diesel with rise of $2.8 \%$ than diesel at full load condition. Every $20 \%$ increase of biodiesel content in blend, $3.64 \%$ increase in EGT was observed.

\subsection{CO Emission}

The variation of $\mathrm{CO}$ emission with engine load (\%) for diesel and different blends of RBOME at constant speed of the engine was illustrated in Figure 4. The $\mathrm{CO}$ emission is found to increase with the increase in 
load and decrease with increase in percentage of RBOME in biodiesel blend. It was observed that the percentage of $\mathrm{CO}$ in all blends was found to be low at all load conditions when compared with diesel fuel. It was also noted that RBOME biodiesel releases CO emission almost an average of $40 \%$ less than diesel and for every $20 \%$ addition of RBOME in biodiesel blend, the $\mathrm{CO}$ emission is reduced by an average of $12-13 \%$. Since RBOME is an oxygenated fuel, it leads to enhanced fuel combustion resulting in the decrease in $\mathrm{CO}$ emission, as $\mathrm{CO}$ is mainly formed due to the inadequate quantity of oxygen to form $\mathrm{CO} 2$. The graph indicates that neat biodiesel has low $\mathrm{CO}$ emission and diesel has the highest in comparison to all the RBOME blends. $\mathrm{CO}$ is mainly formed due to the lack of oxygen and biodiesel is an oxygenated fuel, so it leads to enhanced fuel combustion that resulting in the decrease in $\mathrm{CO}$ emission.

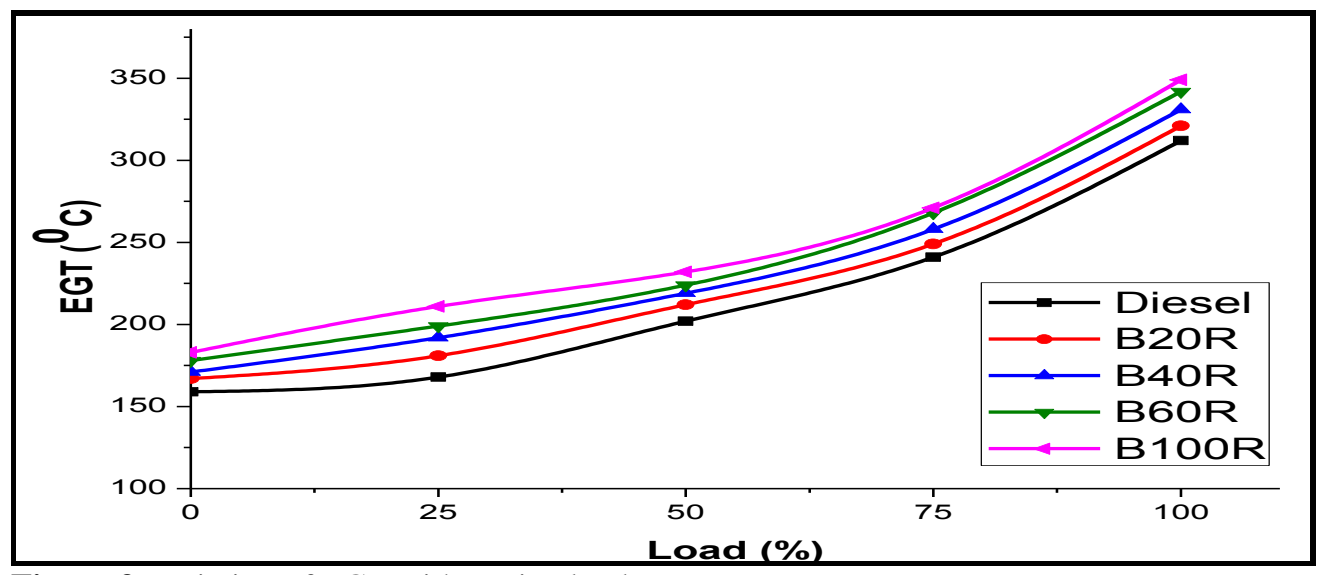

Figure 3 Variation of EGT with engine load

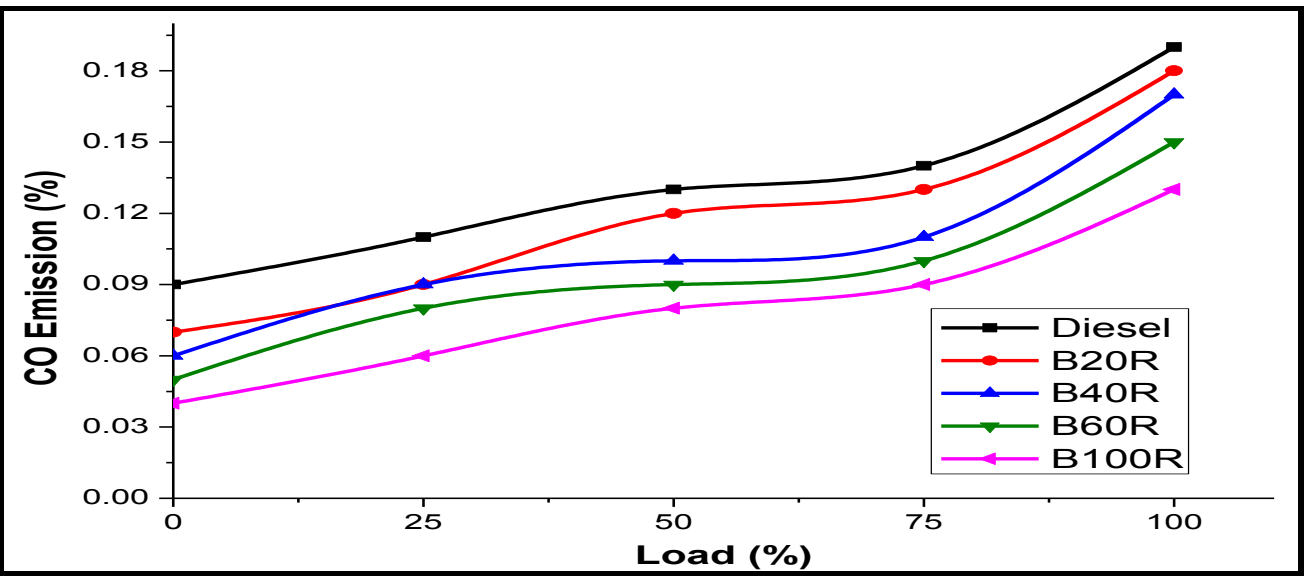

Figure 4 Variation of $\mathrm{CO}$ with engine load

\subsection{Smoke opacity (SOP)}

The variation of smoke opacity of diesel and biodiesel blends for different loads is graphically represented in Figure 5. The graph illustrates that the smoke opacity of neat biodiesel is $20 \%$ less than diesel fuel and increases with the increasing of load for all blends and diesel. As load increases, the smoke opacity also increased. But when biodiesel percentage in blend increases, the smoke opacity has decreased. It is observed that smoke density decreases by $6.8 \%$ with the increase of every $20 \%$ of RBOME in biodiesel blend. The engine has released highest smoke opacity when Diesel used as fuel and lowest opacity emissions when neat biodiesel used as fuel in the test engine.

\subsection{NOx emission}

The variation of NOx emission with biodiesel blends and diesel for different load conditions is graphically 
depicted in Figure 6. It is observed that NOx emission increases with the increase in load for all fuels at constant speed of the engine and increasing with the increase in percentage of RBOME in biodiesel blend. At partial load conditions, the variation of NOx emission of both biodiesel and diesel are comparable.
At medium and full load conditions, NOx emission of RBOME is distinct with neat biodiesel (BR100) having higher values than diesel and their blends. The NOx emission of neat RBOME biodiesel was higher than diesel by an average of $23-24 \%$ and increased by an average of $7 \%$ for every $20 \%$ addition of RBOME percentage in the biodiesel.

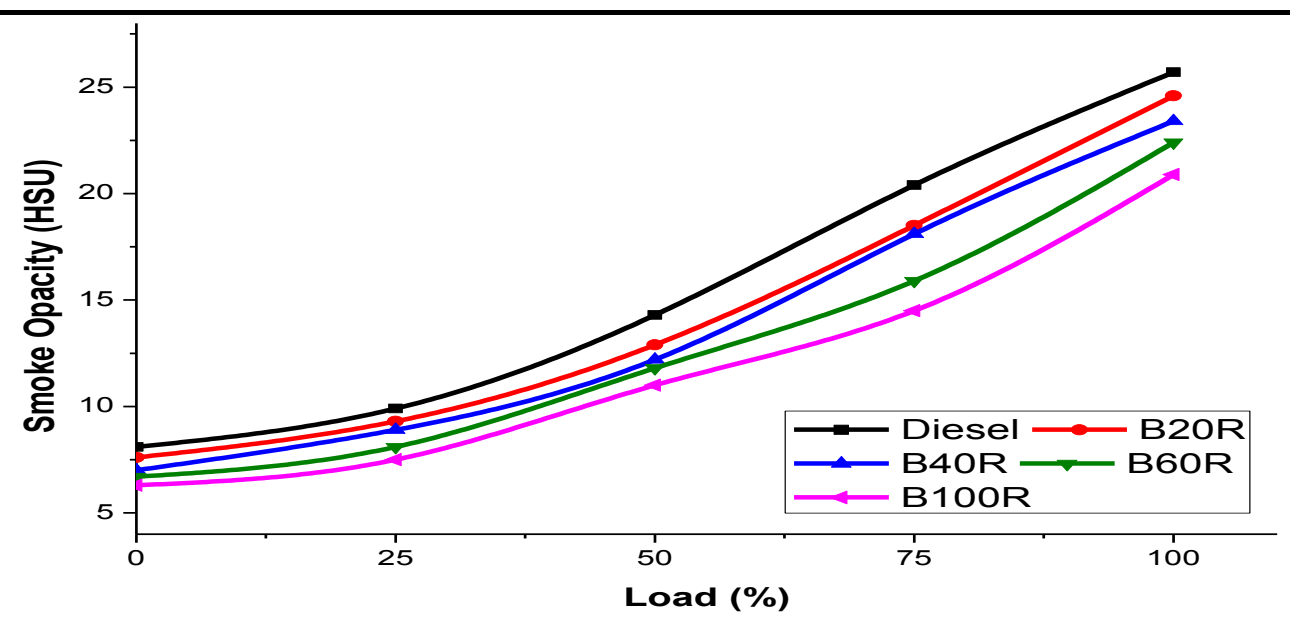

Figure 5 Variation of SOP with engine load

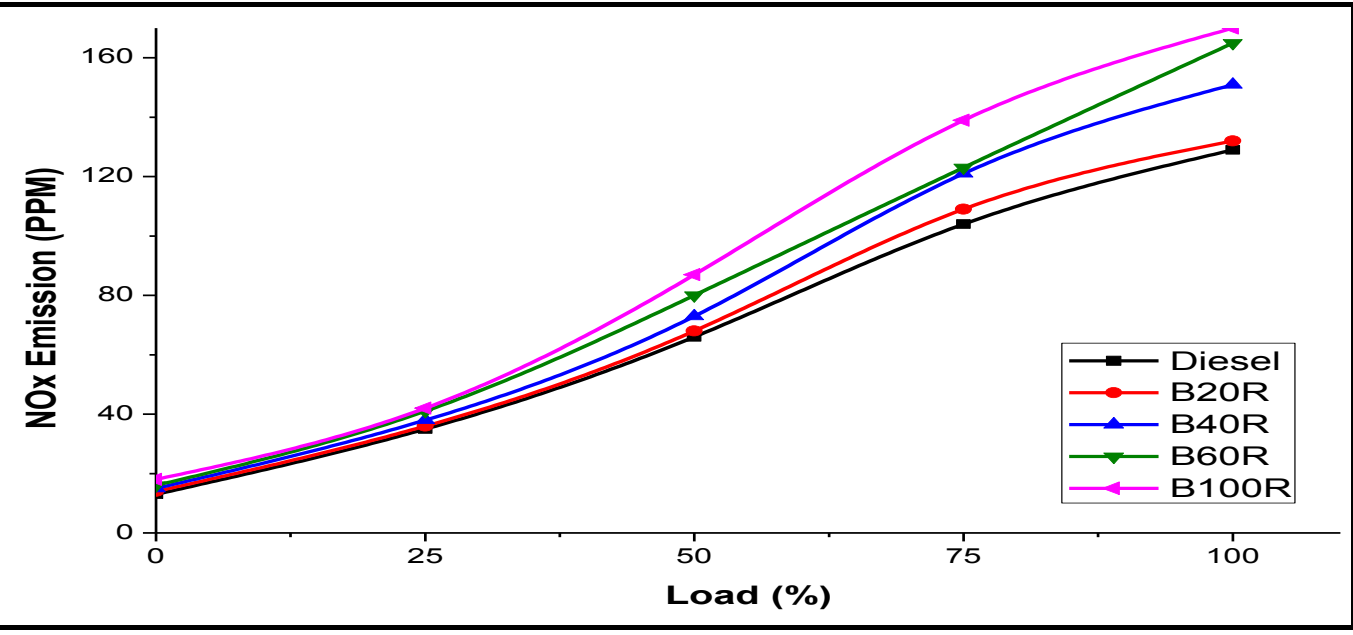

Figure 6 Variation of NOx with engine load

\section{Conclusion}

An experimental results revealed that all tested EGT is higher and emission characteristics: $\mathrm{CO}$, smoke opacity except NOx of biodiesel was less when compared with diesel fuel. NOx emission of neat biodiesel was found to be higher than petro-diesel and all its blends. As a result of transesterification, biodiesel are oxygenated fuel and supports better combustion that results less $\mathrm{CO}$ emission and smoke opacity. Methyl esters with their lower stoichiometric air-fuel ratio can burn biodiesel with less air that causes increase in NOx emission and increases with increase in percentage of methyl esters in the RBOME blends. All emission characteristics were increased with the increase of load at constant engine speed. Test results confirm that biodiesel prepared from rice bran oil can be directly used in diesel engine without modifications and were eco-friendly in nature. It was also observed that as the proportion of rice bran oil methyl ester in the biodiesel was increased, the engine emissions were decreased. 
Bhaskar

Acknowledgment

None.

\section{Conflicts of interest}

The author has no conflicts of interest to declare.

\section{References}

[1] Bala BK. Studies on biodiesels from transformation of vegetable oils for diesel engines. Energy Education Science and Technology. 2005; 15(1/2):1-45.

[2] Kulkarni MG, Dalai AK. Waste cooking oil an economical source for biodiesel: a review. Industrial \& Engineering Chemistry Research. 2006; 45(9):2901-13.

[3] Panwar NL, Shrirame HY, Rathore NS, Jindal S, Kurchania AK. Performance evaluation of a diesel engine fueled with methyl ester of castor seed oil. Applied Thermal Engineering. 2010; 30(2-3):245-9.

[4] Çetinkaya M, Ulusoy Y, Tekìn Y, Karaosmanoğlu F. Engine and winter road test performances of used cooking oil originated biodiesel. Energy Conversion and Management. 2005; 46(7-8):1279-91.

[5] Barnwal BK, Sharma MP. Prospects of biodiesel production from vegetable oils in India. Renewable and Sustainable Energy Reviews. 2005; 9(4):363-78.

[6] Demirbas A. Biofuels securing the planet's future energy needs. Energy Conversion and Management. 2009; 50(9):2239-49.

[7] Canakci M. Performance and emissions characteristics of biodiesel from soybean oil. Proceedings of the Institution of Mechanical Engineers, Part D: Journal of Automobile Engineering. 2005; 219(7):915-22.

[8] Altın R, Cetinkaya S, Yücesu HS. The potential of using vegetable oil fuels as fuel for diesel engines. Energy Conversion and Management. 2001; 42(5):529-38

[9] Barsic NJ, Humke AL. Performance and emissions characteristics of a naturally aspirated diesel engine with vegetable oil fuels. SAE Transactions. 1981:1173-87.

[10] Gattamaneni RN, Subramani S, Santhanam S, Kuderu R. Combustion and emission characteristics of diesel engine fuelled with rice bran oil methyl ester and its diesel blends. Thermal Science. 2008; 12(1):139-50.
[11] Nabi MN, Rahman MM, Akhter MS. Biodiesel from cotton seed oil and its effect on engine performance and exhaust emissions. Applied Thermal Engineering. 2009; 29(11-2):2265-70.

[12] Qi DH, Geng LM, Chen H, Bian YZ, Liu J, Ren XC. Combustion and performance evaluation of a diesel engine fueled with biodiesel produced from soybean crude oil. Renewable Energy. 2009; 34(12):2706-13.

[13] Bhaskar SV. Experimental investigation on performance of DI diesel engine using madhuca indica biodiesel and its diesel blends. International Journal of Scientific Research in Science and Technology. 2018; 4(2):565-9.

[14] Hasan MM, Rahman MM. Performance and emission characteristics of biodiesel-diesel blend and environmental and economic impacts of biodiesel production: a review. Renewable and Sustainable Energy Reviews. 2017; 74:938-48.

[15] Dubé MA, Tremblay AY, Liu J. Biodiesel production using a membrane reactor. Bioresource Technology. 2007; 98(3):639-47.

[16] Sharma YC, Singh B. Development of biodiesel: current scenario. Renewable and Sustainable Energy Reviews. 2009; 13(6-7):1646-51.

[17] Leung DY, Wu X, Leung MK. A review on biodiesel production using catalyzed transesterification. Applied Energy. 2010; 87(4):1083-95.

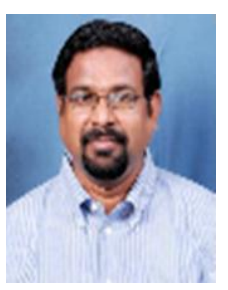

Sirivella Vijaya Bhaskar received his B.Tech degree in Mechanical Engineering from Jawaharlal Nehru Technological University (JNTU), Anantapur, India, M.Tech in Machine Design from Jawaharlal Nehru Technological University (JNTU), Kakinada, India. PhD degree in Industrial Management from Sri Krishnadevaraya University, Anantapur, India and Ph.D. degree in Mechanical Engineering from JNTUH University, Hyderabad, India. Currently working as Professor in Mechanical Engineering, Sreenidhi Institute of Science and Technology, Ghatkesar, Hyderabad, India. His research interest includes, but not limited to Renewable Energy, Product Innovation, ANN, Optmization Techniques, Industrial Engineering and Biodiesel.

Email: sbvijay@gmail.com 